Jurnal Kebidanan 09 (02) 101 - 212

Jurnal Kebidanan

http : /www.journal.stikeseub.ac.id

\title{
EFEKTIFITAS PEMBERIAN EKSTRAK BAYAM TERHADAP PENINGKATAN KADAR HEMOGLOBIN PADA IBU HAMIL DENGAN ANEMIA RINGAN
}

\author{
Dheny Rohmatika ${ }^{1}$, Tresia Umarianti ${ }^{2)}$ \\ ${ }^{1,2}$ Prodi DIII Kebidanan STIKes Kusuma Husada Surakarta \\ Email: dhenyr82@gmail.com; t27a.umarianti@gmail.com
}

\begin{abstract}
ABSTRAK
Anemia sering terjadi akibat defisiensi zat besi karena pada ibu hamil terjadi peningkatan kebutuhan zat besi dua kali lipat akibat peningkatan volume darah tanpa ekspansi volume plasma, untuk memenuhi kebutuhan ibu. Salah satu alternatif untuk memenuhi kebutuhan zat besi dapat dilakukan dengan konsumsi sayuran yang mengandung zat besi dalam menu makanan. bayam hijau merupakan salah satu sumber makanan yang mengantung senyawa yang diperlukan dalam sintesis hemoglobin seperti zat besi dan vitamin B Komplek. Tujuan Penelitian Membuktikan Pengaruh Pemberian Ekstrak Bayam Hijau Terhadap Perubahan Kadar Hemoglobin Ibu Hamil Pasien Puskesmas. Metode Penelitian. T-test dependent, T-test independent. Pengukuran hemoglobin menggunakan alat Hemoglobin Testing System Quick-Check set. Hasil Penelitian Penelitian dilakukan pada 34 responden selama 7 hari. Hasil uji uji paired sample t-test diperoleh t: 4,716 dan nilai p 0,000 ( $\mathrm{p}<0.05)$ didapatkan nilai $\mathrm{p}<0,05$. Kesimpulan Pemberian Ekstrak Bayam Hijau secara signifikan mempengaruhi perubahan kadar Hemoglobin.
\end{abstract}

Kata Kunci : Bayam Hijau, Kadar Hemoglobin, Ibu Hamil

EFFECTIVENESS GIVE OF BAYAM EXTRACT AGAINTS ENHANCEMENT LEVELS HEMOGLOBIN ON MOTHER PREGNANT WITH MILD ANEMIA

\begin{abstract}
Anemia often occurs due to iron deficiency because in pregnant women there is an increase in iron demand doubled due to increased blood volume without expansion of plasma volume, to meet the needs of the mother. One alternative to meet the needs of iron can be done with the consumption of vegetables containing iron in the diet. green spinach is one of the food sources that mengantung compounds required in the synthesis of hemoglobin such as iron and vitamin B complex. Objective Proving Comparison Effect of Extract Green Spinach With Fe Mixture Against Pregnancy Hemoglobin Change Patient Health Center. Research Method Dependent T-test, independent ttest. Measurement of hemoglobin using the tool Hemoglobin Testing System Quick-Check sets. Results The study was conducted on 34 respondents for 7 days. The test results of paired sample $t$ test obtained t: 4,716 and $p$ value 0,000 ( $p<0.05$ ) got $p$ value <0,05. Conclusion The Giving Green Spinach Extract significantly affect change in hemoglobin levels.
\end{abstract}

Keywords : Green Spinach, Hemoglobin, Pregnant Women 


\section{PENDAHULUAN}

Program kesehatan Ibu dan Anak merupakan salah satu prioritas Kementerian Kesehatan dan keberhasilan program KIA menjadi salah satu indikator utama dalam Rencana Pembangunan Jangka Panjang Nasional (RPJPN) 2005 - 2025. Salah satunya indikator keberhasilan pembangunan dalam bidang kesehatan dapat dilihat dari tinggi rendahnya angka kematian ibu dan bayi. Berdasarkan survey SDKI tahun 2012 angka kematian ibu di Indonesia mencapai 359 kematian per 100.000 keahiran hidup. Jumlah ini meningkat di bandingkan data SDKI 2007 yang besarnya 228 kematian dan masih merupakan tertinggi di Asia. Selain masih rendahnya kesadaran akan kesehatan ibu hamil, beberapa penyebab kematian ibu melahirkan antara lain perdarahan, hipertensi saat hamil atau pre eklamsia dan infeksi.

Departemen Kesehatan RI memberikan standar pelayanan pemeriksaan ANC selama hamil sedikitnya $4 \mathrm{x}$ pelayanan antenatal yaitu satu kali untuk trimester I, satu kali untuk trimester II, dan dua kali untuk trimester III, pemeriksaan meliputi anamnesa dan pemantauan ibu dan janin dengan seksama untuk menilai apakah perkembangan berlangsung normal. Bidan juga harus mengenal kehamilan resiko tinggi khususnya anemia kurang gizi, hipertensi. Bidan juga memberikan nasehat dan penyuluhan kesehatan serta tugas terkait lainnya. Dalam setiap kunjungan ANC bidan menonjolkan kepada ibu hamil apakah persediaannya cukup

Menurut Rencana Strategis Kementerian Kesehatan tahun 2015-2019 angka kejadian ibu hamil dengan anemia sebesar 37,1\% (Depkes, 2015).

Anemia yang terjadi pada ibu hamil akan berdampak pada ibu dan bayinya. Dampak yang ditimbulkan antara lain, abortus, kurang tenaga saat melahirkan sehingga partus lama dan infeksi pada ibu dan bayinya, perdarahan pada waktu melahirkan, kelahiran prematur, bayi lahir dengan berat lahir rendah serta janin mengalami kekurangan gizi saat dalam kandungan intra uterine growth retardation IUGR). Anemia pada ibu hamil juga akan menyebabkan tingginya angka kematian ibu (AKI).

Kebijakan pemerintah dalam menangani masalah anemia pada kehamilan adalah pemberian suplementasi besi dan asam folat. World Health Organitation menganjurkan untuk memberikan $60 \mathrm{mg}$ besi selama 6 bulan untuk memenuhi kebutuhan fisiologik selama kehamilan, namun bayak literatur yang menanjurkan dosis $100 \mathrm{mg}$ besi setiap hari selama 16 minggu atau lebih pada kehamilan. Di wilayah - wilayah 
dengan prevelensi anemia yang tinggi dianjurkan untuk memberikan suplementasi zat besi sampai tiga bulan post partum (Fatimah H, 2011).

Selain itu program RPJMN untuk menanggulangi kejadian anemia di Indonesia telah ditetapkan pada strategi pertama yaitu, kesehatan ibu dan anak, dan perbaikan gizi (secara spesifik, PMT, fortifikasi, suplementasi, fokus 1.000 HPK, remaja, calon pengantin dan ibu hamil terutama untuk keluarga miskin dan DTPK) (Depkes, 2015).

Dalam memenuhi kebutuhan zat besi, seseorang biasanya mengkonsumsi suplemen, akan tetapi salah satu alternatif untuk memenuhi kebutuhan zat besi dapat dilakukan dengan konsumsi sayuran yang mengandung zat besi dalam menu makanan. Zat besi ditemukan pada sayur-sayuran, antara lain bayam (Amaranthus spp.). Sayuran berhijau daun seperti bayam adalah sumber besi nonheme. Bayam yang telah dimasak mengandung zat besi sebanyak 8,3 mg/100 gram. menambahkan, kandungan zat besi pada bayam berperan untuk pembentukan haemoglobin (Fatimah S, 2009)

Bayam hijau memiliki manfaat baik bagi tubuh karena merupakan sumber kalsium, vitamin A, vitamin $\mathrm{E}$ dan vitamin $\mathrm{C}$, serat, dan juga betakaroten. Selain itu, bayam juga memiliki kandungan zat besi yang tinggi untuk mencegah anemia.kandungan mineral dalam bayam cukup tinggi, terutama Fe yang dapat digunakan untuk mencegah kelelahan akibat anemia. Karena kandungan $\mathrm{Fe}$ dalam bayam cukup tinggi, ditambah kandungan Vitamin B terutama asam folat (Rukamana, 2006).

Hal ini sesuai dengan penelitian Fatimah (2009), dalam studi klorofil dan zat besi $(\mathrm{Fe})$. berdasarkan kadar klorofil dan zat besi menunjukkan jenis bayan hijau (Amaranthus hybridus) lebih dapat memberikan pngaruh nyata terhadap jumlah eritrosit tikus putih anemia dibandingkan tiga jenis bayam lainnya. Penelitian Susiloningtyas (2010), Pemberian preparat Fe sebesar $60 \mathrm{mg}$ selama 30 hari dapat menaikan kadar $\mathrm{Hb}$ sebanyak 1 gr\%. Pemberian preparat $\mathrm{Fe}$ sebesar $60 \mathrm{mg}$ selama 30 hari dapat menaikan kadar $\mathrm{Hb}$ sebanyak $1 \mathrm{gr} \%$.

\section{METODE}

Jenis penelitian ini adalah penelitian eksperimen semu atau quasy experiment dengan rancangan Randomized pretest and posttest with control group design. Jumlah populasi 56 orang, jumlah sampel 34 orang. Lokasi penelitian ibu hamil di puskesmas Gambirsari Surakarta dengan alasan penyelenggaraan pelayanan kesehatan di 
Kecamatan Banjarsari masih terdiri dari 1 puskesmas induk dan 2 unit puskesmas pembantu. Terdapat juga 10 praktik dokter dan 9 rumah bersalin (milik swasta). Penyelenggaraan Upaya Kesehatan Ibu dan Anak (KIA) salah satu kegiatan utamanya adalah kunjungan Ibu hamil (K1 dan K4) untuk memperoleh pelayanan sesuai standar $10 \mathrm{~T}$. Dari laporan kinerja KIA pada tahun 2014 diketahui bahwa cakupan kunjungan ibu hamil (K4) sebesar 90.96\%, distribusi dan cakupan pemberian tablet $\mathrm{Fe}$ mencapai $90.96 \%$.

Penelitian dilaksanakan di wilayah kerja puskesmas Gambirsari dibantu oleh tenaga enumerator (bidan desa 5 orang, tenaga laboratorium 1 orang dan 6 kader). Pelaksanaan proses pengambilan data dimulai dengan pengumpulan data jumlah ibu hamil secara keseluruhan sampai bulan November 2015, diperoleh data jumlah ibu hamil trimester II dan III sebanyak 78 orang. Pengkajian 34 orang ibu hamil trimester II-III, ibu hamil yang memenuhi kriteria inklusi akan dijadikan sampel setelah mendapat persetujuan secara tertulis dari ibu hamil dengan menandatangani lembar informed consent.

Analisa Univariat dengan uji homogenitas bertujuan untuk melihat kesetaraan antara variabel, data kategorik meliputi umur, pendidikan, pekerjaan, paritas, umur kehamilan yang mendapat ekstrak bayam hijau dengan menggunakan uji chi square test. Analisa data menggunakan uji paried t-test. Uji statistik menggunakan interval kepercayaan (confidience interval) 95\%.

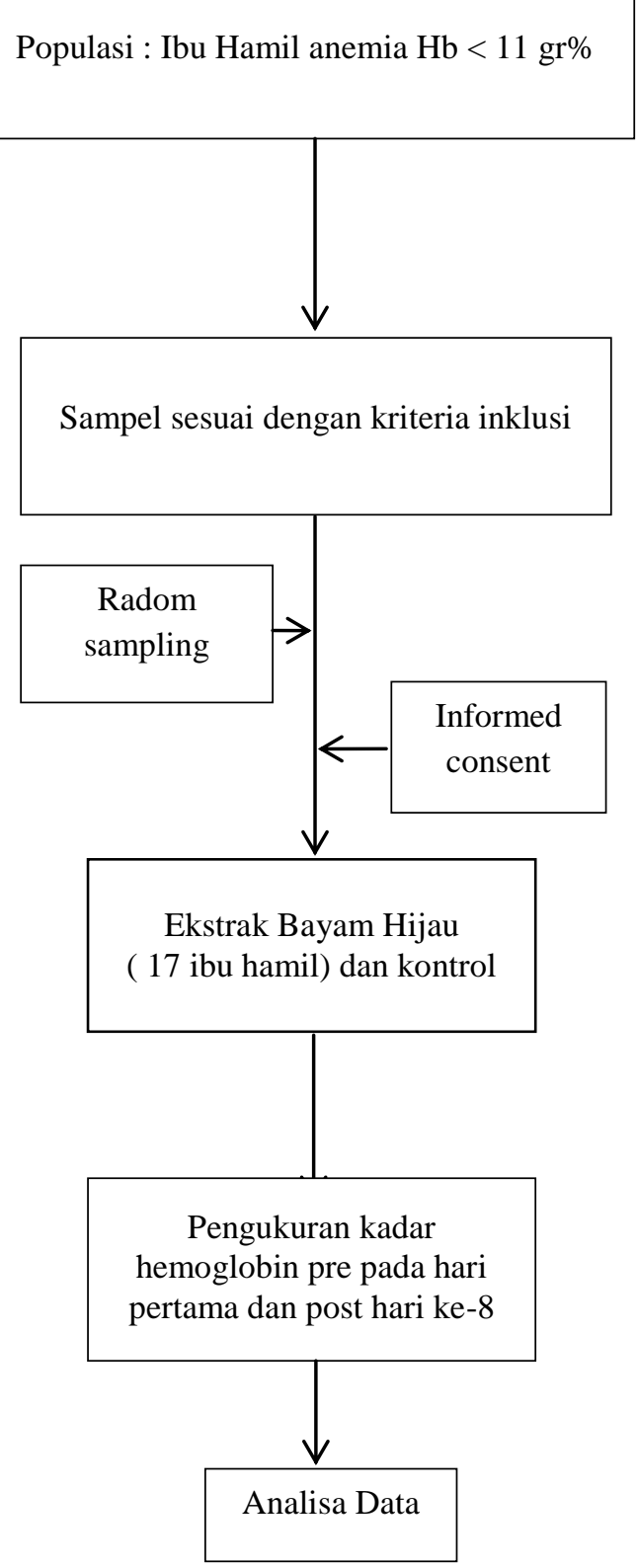




\section{HASIL DAN PEMBAHASAN}

Hasil penelitian yang dilaksanakan di wilayah kerja puskesmas Gambirsari adalah sebagai berikut:

Tabel 1 Distribusi Responden berdasarkan karakteristik umur, pendidikan, pekerjaan, paritas dan umur kehamilan di wilayah kerja Puskesmas Gambirsari kota Surakarta.

\begin{tabular}{lccccccc}
\hline \multicolumn{1}{c}{$\begin{array}{c}\text { Karakteristik } \\
\text { Responden }\end{array}$} & \multicolumn{2}{c}{$\begin{array}{c}\text { Ekstrak bayam } \\
\text { Hijau }\end{array}$} & \multicolumn{7}{c}{ Suplemen tablet Fe } & $\begin{array}{c}\text { Jumlah } \\
\text { total }\end{array}$ & $\begin{array}{c}\% \\
\text { Total }\end{array}$ & P \\
\cline { 2 - 8 } & Jlh & $\%$ & Jlh & $\%$ & & & \\
\hline Umur & 0 & 0 & 0 & 0 & 0 & 0 & 0,1 \\
$20-35$ & 17 & 50.0 & 17 & 50.0 & 34 & 100 & \\
$>35$ & 0 & 0 & 0 & 0 & 0 & 0 & \\
Pendidikan & & & & & & & \\
Dasar & 6 & 42.9 & 8 & 57.1 & 14 & 100 & 0.134 \\
Menengah & 9 & 50.0 & 9 & 50.0 & 18 & 100 & \\
Tinggi & 2 & 100 & 0 & 0 & 2 & 100 & \\
Pekerjaan & & & & & & & \\
Bekerja & 6 & 54.5 & 5 & 45.5 & 11 & 100 & 0.714 \\
Tidak bekerja & 11 & 47.8 & 12 & 52.2 & 23 & 100 & \\
Paritas & & & & & & & \\
1x & 11 & 52.4 & 10 & 47.6 & 21 & 100 & 0.724 \\
$>$ 1x & 6 & 46.2 & 7 & 53.8 & 13 & 100 & \\
UK & & & & & & & \\
TM II & 6 & 37.5 & 10 & 62.5 & 16 & 100 & 0.169 \\
TM III & 11 & 61.1 & 7 & 38.9 & 18 & 100 & \\
\hline & & & & & & & \\
\hline
\end{tabular}

Berdasarkan dari hasil analisa variabel umur pada kelompok I dan II adalah homogen/setara yaitu dengan nilai $\mathrm{P}=0,1 \quad(>0,05)$, yang menunjukkan bahwa keseluruhan sampel masuk dalam kategori umur tidak beresiko tinggi yaitu sebanyak 17 orang (50\%) pada masingmasing kedua kelompok.

Berdasarkan dari hasil analisa status pendidikan pada kelompok I dan II adalah homogen/setara yaitu dengan nilai $P=0,134(>0,05)$. Respoden tingkat pendidikan pada kelompok I pendidikan dasar sebanyak $6(42,9 \%)$, menengah sebanyak $9(50,0 \%)$ dan tinggi sebanyak 2 (100\%), sedangkan pada kelompok II adalah kategori kategori pendidikan dasar sebanyak $8(57,1 \%)$, menengah sebanyak 9 (50,8\%). Untuk mayoritas responden karakteristik 
pendidikan ibu hamil pada kelompok I dan II berpendidikan menengah.

Berdasarkan dari hasil analisa status pekerjaan ibu hamil pada kelompok I dan II adalah homogen/setara yaitu dengan nilai $\mathrm{P}=0,714(>0,05)$. Ibu hamil yang bekerja pada kelompok I sebanyak 6(54,5\%) dan yang tidak bekerja sebanyak $11(47,8 \%)$, sedangkan pada kelompok II ibu hamil yang bekerja sebanyak $5(45,5,3 \%)$ dan yang tidak bekerja sebanyak 14 (56\%). berdasarkan karakteristik pekerjaan menunjukkan bahwa mayoritas responden ibu hamil kelompok 1 dan II tidak bekerja.

Berdasarkan dari hasil analisa status paritas ibu hamil pada kelompok I dan II adalah homogen/setara yaitu dengan nilai $\mathrm{P}=0,724(>0,05)$. Ibu hamil pertama kali (primipara) pada kelompok I sebanyak $11(52,4 \%)$ dan paritas yang lebih dari satu sebnayak 6 (46,2\%), sedangkan pada kelompok II ibu hamil pertama kali sebanyak $10(47,6 \%)$ dan paritas yang lebih dari satu kali sebanyak 7 (53,8\%). Karakteristik Responden paritas menunjukkan bahwa mayoritas ibu hamil kelompok I dan II adalah primigravida.

Berdasarkan dari hasil analisa umur kehamilan pada kelompok I dan II adalah homogen/setara yaitu dengan nilai $\mathrm{P}=0,169(>0,05)$. Umur kehamilan pada kelompok I yang termasuk pada trimester 2 sebanyak $6(37,5 \%)$ dan trimester 3 sebanyak $11(61,1 \%)$, sedangkan pada kelompok II yang termasuk trimester 2 sebanyak $10(62,5 \%)$ dan trimester 3 sebanyak 7 (38.9\%). Karakteristik respoden berdasarkan umur kehamilan menunjukkan bahwa mayoritas responden ibu hamil trimester III.

Tabel 2. Hasil pengukuran kadar hemoglobin sebelum dan sesudah konsumsi ekstrak bayam hijau di wilayah Kerja Puskesmas Gambirsari Kota Surakarta $(\mathrm{N}=17)$

\begin{tabular}{lccc}
\hline $\begin{array}{c}\text { Kelompok } \\
\text { I }\end{array}$ & Mean & $\begin{array}{c}\text { Nilai Hb } \\
\text { minimal }\end{array}$ & $\begin{array}{c}\text { Nilai Hb } \\
\text { maksimal }\end{array}$ \\
\hline $\begin{array}{l}\text { Sebelum } \\
\begin{array}{l}\text { Intervensi } \\
\text { Setelah }\end{array}\end{array}$ & 10.06 & 9.1 & 10.8 \\
$\begin{array}{l}\text { Intervensi } \\
(7 \text { hari })\end{array}$ & 10.60 & 9.7 & 12.4 \\
\hline
\end{tabular}

Berdasarkan tabel 2 menunjukkan bahwa pemeriksaan kadar $\mathrm{Hb}$ dilakukan pada awal dan akhir penelitian. Hasil penellitian menunjukkan bahwa rerata kadar $\mathrm{Hb}$ awal sebesar 10,06 g/dl, rerata $\mathrm{Hb}$ akhir 10,60 g/dl. Rerata kadar $\mathrm{Hb}$ awal 10,06 g/dl dengan nilai minimum 9,1 g/dl dan maksimum 10,8 g/dl. Rerata kadar $\mathrm{Hb}$ akhir 10,60 g/dl dengan nilai minimum 9,7 g/dl dan maksimum 12,4 g/dl. Gambaran selengkapnya dapat dilihat dalam gambar 1 dibawah ini.

Kadar Hb Sebelum dan Sesudah Pemberian Ekstrak Daun Bayam

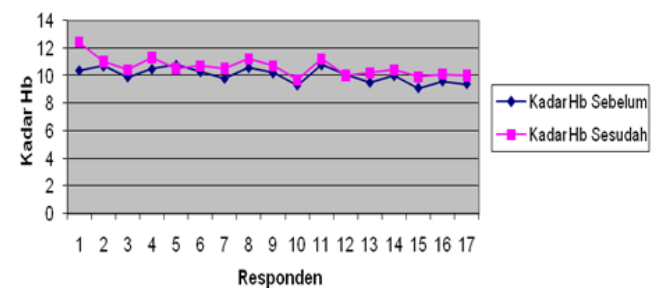


Gambar 1

Kadar Hemoglobin sebelum dan sesudah pemberian ekstrak bayam hijau di wilayah kerja Puskesmas Gambisari Kota Surakarta

Provinsi Jawa Tengah $(\mathrm{N}=17)$

Analisa Bivariat, dapat dilihat dari beberapa tabel.

Tabel 3. Uji normalitas kadar hemoglobin sebelum dan sesudah konsumsi ekstrak bayam hijau di wilayah Kerja Puskesmas Gambirsari Kota Surakarta $(\mathrm{N}=17)$

\begin{tabular}{lccc}
\hline \multicolumn{1}{c}{ Kelompok II } & Mean & SD & Sig. \\
\hline Sebelum Intervensi & 10.06 & 0.54 & 0.483 \\
$\begin{array}{l}\text { SetelahIntervensi } \\
\text { (7 hari) }\end{array}$ & 10.66 & 0.67 & 0.125 \\
\hline
\end{tabular}

Berdasarkan tabel 3 di atas dapat dilihat bahwa hasil uji normalitas dengan menggunakan shapiro wilk hasil sebelum dilakukan intervensi selama 7 hari nilai signifikansi lebih besar dari nilai alpha. Nilai $(0.483>0.05)$ dan sesudah intrvesi nilai signifkansi $(0.125>0.05)$ maka $\mathrm{H}_{0}$ diterima, yang artinya kadar hemoglobin sebelum dan sesudah intervensi pada perlakuan pemberian ekstrak bayam hijau berdistribusi normal sehingga menggunakan uji paired sample t-test. Hasil uji paired sample t-test diperoleh nilai t: 4,716 dan nilai $p \quad 0,000$ $(p<0.05)$ yang berarti ada perbedaan yang signifikan kadar hemoglobin sebelum dan sesudah pemberian ekstrak bayam hijau. Hal ini dapat dilihat dalam tabel 4 uji paired sample t-test berikut ini.

Tabel 4. Uji normalitas paired sample t-test kadar hemoglobin sebelum dan sesudah konsumsi ekstrak bayam hijau di wilayah Kerja Puskesmas Gambirsari Kota Surakarta $(\mathrm{N}=17)$

\begin{tabular}{ccccccc}
\hline & & \multicolumn{5}{c}{$95 \% \mathrm{CI}$} \\
Intervensi & Mean & SD & Lower & Upper & T & $P$ \\
Ekstrak Bayam & 0.541 & 0.473 & 0.297 & 0.784 & 4.716 & 0.000 \\
Hijau & & & & & & \\
\hline
\end{tabular}

Dari hasil penelitian ini dapat disimpulkan bahwa ada perbedaan kadar hemoglobin darah sebelum dengan sesudah diberikan ekstrak bayam hijau dimana dengan menggunakan uji paired sample t-test diperoleh t: 4,716 dan nilai p 0,000 $(p<0.05)$ didapatkan nilai $\mathrm{p}<$ 0,05 . Hal ini menunjukkan bahwa hipotesis nol ditolak.

Bayam hijau merupakan salah satu alternatif untuk memenuhi kebutuhan zat besi dapat dilakukan dengan konsumsi sayuran yang mengandung zat besi dalam menu makanan. Zat besi ditemukan pada sayur-sayuran, antara lain bayam (Amaranthus spp.). Sayuran berhijau daun seperti bayam adalah sumber besi nonheme. Bayam yang telah dimasak mengandung zat besi sebanyak 8,3 mg/100 gram. menambahkan, kandungan zat besi pada bayam berperan untuk pembentukan haemoglobin (Fatimah, 
2009). Bayam hijau memiliki manfaat baik bagi tubuh karena merupakan sumber kalsium, kandungan vitamin pada bayam adalah vitamin A, B2, B6, B12, C, $\mathrm{K}$, mangan, magnesium, zat besi, kalsium, kalium, dan fosfor. serat, dan juga betakaroten. Selain itu, bayam juga memiliki kandungan zat besi yang tinggi untuk mencegah anemia.kandungan mineral dalam bayam cukup tinggi, terutama Fe yang dapat digunakan untuk mencegah kelelahan akibat anemia. Bayam hijau mudah diolah menjadi berbagai macam makanan atau ekstrak herbal yang lebih variatif dibanding dengan bahan makanan lain mengandung Fe. Kadar besi tersebut dapat membantu pembentukan hem dan globin dalam tubuh.

Peningkatan kadar $\mathrm{Hb}$ ibu hamil tidak hanya dipengaruhi oleh pemberian suplement Fe semata tetapi didukung oleh konsumsi makanan yang mengandung vitamin B6 dan vitamin B12 yang dibutuhkan dalam sintesis hemoglobin. Untuk sintesis globin diperlukan asam amino, biotin, asam folat, vitamin B6 dan vitamin B12. Selanjutnya interaksi antara heme dan globin akan menghasilkan hemoglobin. Berdasarkan hal tersebut, maka dapat disimpulkan bahwa untuk sintesis hemoglobin diperlukan beberapa zat gizi yang saling terkait (Guyton dkk, 2008).
Hal yang tidak kalah penting secara teori adalah kandungan vitamin $\mathrm{C}$ bayam yang cukup tinggi, yaitu 80 $\mathrm{mg} / 100 \mathrm{~g}$. Faktor-faktor tanaman bayam hijau yang dapat membantu terjadinya induksi zat besi dalam tubuh sehingga mampu berikatan dengan gugus heme pada molekul hemoglobin anatara lain vitamin $\mathrm{C}$, Vitamin $\mathrm{B}_{6}$, folat dan isoleusin. Kandungan Vit $\mathrm{C}$ pada bayam berfungsi mengubah Feri menjadi fero, sehingga zat besi yang ada dalam tubuh mampu berikatan dengan oksigen. Vitamin $B_{6}$ dan folat berperan dalam pembentukan darah. Isoleusin merupakan suatu asam amino esensial yang memiliki peran utama dalam pembentukan sel darah merah. Hal ini dibuktikan dengan adanya peningkatan kadar $\mathrm{Hb}$ yang signifikan setelah konsumsi ekstrak bayam hijau.

Penelitian Kumar (2012), bahwa bayam sayuran hijau dapat meningkatkan kadar hemoglobin, serta penelitian Anggreini (2014), bahwa bayam hijau dapat menigkatkan kadar hemoglobin pada mencit yang mengalami anemia. Penelitian Fajria (2009), menggunakan bayam merah (Amaranthus gageticus) meningkatkan kadar hemoglobin pada mencit 29,32\% yang dibandingkan dengan suplemen penambah darah dikarenakan bayam merah memiliki faktor tanaman yang 
dapat membantu sintesis hemoglobin. kadar zat besi pada larutan bayam merah diiukur dengan menggunakan Atomic Absorption spectroscopy (AAS).

\section{PENUTUP}

Mengkonsumsi esktrak bayam hijau selama 7 hari dapat meningkatkan kadar hemoglobin pada ibu hamil dengan rata-rata peningkatan sebesar $0.541 \mathrm{gr} / \mathrm{dl}$.

Dalam 1 gr bayam hijau yang sudah dilakukan ekstraksi di Lab. Teknologi Pangan UNS dan Fresh dryer di Lab SEFA UMS dan analisis kandungan dengan metode AAS di Lab. MIPA UNS terdapat kandungan zat besi sebesar $21 \mathrm{mg} / \mathrm{gr}$. Bayam hijau merupakan sumber zat besi yang dapat membantu terjadinya induksi zat besi dalam tubuh sehingga mampu berikatan dengan gugus heme pada molekul hemoglobin anatara lain vitamin $\mathrm{C}$, Vitamin $\mathrm{B}_{6}$, folat dan isoleusin. Kandungan Vit C pada bayam berfungsi mengubah Feri menjadi fero, sehingga zat besi yang ada dalam tubuh mampu berikatan dengan oksigen. Vitamin $\mathrm{B}_{6}$ dan folat berperan dalam pembentukan darah. Isoleusin merupakan suatu asam amino esensial yang memiliki peran utama dalam pembentukan sel darah merah. Hal ini dibuktikan dengan adanya peningkatan kadar $\mathrm{Hb}$ yang signifikan setelah konsumsi ekstrak bayam hijau dengan uji statistik nilai signifikansi lebih kecil dari nilai alpa $p$ $0,000(p<0.05)$.

\section{DAFTAR PUSTAKA}

Anggraeni, Ika esti. Pengaruh Bayam (Amarathus) terhadap perubahan Hemoglobin (studi laboratorium pada mencit). (Tesis). 2014

Aril. Fisiologis Tubuh Manusia. Jakarta: KDT. 2009; 123-131

Arisman. 2010. Buku Ajar Gizi untuk Kebidanan. Penerbit Muha Medika. Jogyakarta.

Cuningham, G. William Obstetri. Edisi 21 jakarta: ECG. 2007; 58-63

Depkes, 2015. Rencana Strategi Kementerian Kesehatan 20152019.www.depkes.go.id/resources/ download/info-publik/Renstra2015.pdf

Guyton Arthur C and Hall, John E. Buku Ajar Fisiologi Kedokteran, edisi 11.EGC. Jakarta. 2008; 440-448

Darmawan Oki. Studi Green corrosion inhibitor daun bayam merah (amarathus ganggeticus) pada baja karbon rendah dalam larutan IM HCL dengan polarisasi dan EIS. 2012. Universitan Indonesia. Jurnal Nasional.

Fajria. Pengukuran zat besi dalam bayam merah dan kadar hemoglobin suplemen penambah darah serta pengarunya terhadap peningkatan zat besi dalam darah. (Tesis). 2011

Fatimah, Hadju et al. Pola Konsumsi dan Kadar Hemoglobin Pada Ibu Hamil Di Kabupaten Maros,Sulawesi Selatan. Makara,Kesehatan. 2011; Vol. 15(1): 31-36

Fatimah, Siti. Studi Kadar Klorofil dan zat besi (fe) pada beberapa jenis bayam terhadap jumlah eritrosit tikus putih (rattus norvegicus) anemia. UIN Malang. (Tesis). 2009

Hinderaker SG, Olsen BE, Lie RT, et al. (2010). Anemia in pregnancy in rural Tanzania: associations with micronutrients status and 
infections. Eur. J. Clin. Nutr. 2010 ; 56(3):192-199

Johson Trevor. 2011. Vitamin in Spinach.

hhtp://www.spinach.word.com.

Linda J Harvey, Jack R Dainty, Wendy Hollands, et al. 2007. Effect of high-dose iron supplements on fractional zinc absorption and status in pregnant women. American Journal of Clinical Nutrition, Vol. 85, No. 1

Manuaba, I.B.G., I.A. Pengantar Kuliah Obstetri. Jakarta : Buku Kedokteran ECG. 2010; 44-46, 89.

Midelton. Meatment For womenwith post iron defisiency anemia (review) the cochrane library wiley. Jurnal Internasional. (Tesis). 2007.

Morris. 2008. Amarathus hibridus, amarathus gangentisus, Amarathus spinosus, Amarathus Blitum. England: Plant For or Future.

Muwakhidah. 2009. Efek suplementasi Fe, Asam Folat dan Vitamin B12 Terhadap peningkatan kadar Hemoglobin $(\mathrm{Hb})$ pada pekerja wanita di kabupaten sukoharjo. Tesis. Jurnal nasional

Ojofeitimi EO, Ogunjuyigbe PO, Sanusi, et al. 2008. Poor Dietary Intake of Energy and Retinol among Pregnant Women: Implications for Pregnancy Outcome in Southwest Nigeria. Pak. J. Nutr.; 7(3):480484.

Prawiroharjo. Buku Pedoman Praktis Pelayanan Kesehatan Maternal. Jakarta: Yayasan Bina Pustaka Sarwono Prawirohardjo. 2010; 263-271

Proverawati, Atikah. Anemia dan Anemia kehamilan. Yogyakarta : Nuha Medika. 2007;54-82

Rohmatika D, Supriyana, Djamaluddin R. 2016. Perbandingan pengaruh pemberian Ekstrak bayam hijau dengan preparat fe terhadap perubahan kadar hemoglobin Ibu hamil pasien puskesmas. Jurnal KesMaDasKa Vol 7, No 1 (2016).

Rohmatika D dan Umarianti T. 2017. Uji Laboratorium

Pengukuran
Kandungan Zat Besi (Fe) Pada Ekstrak Bayam Hijau (Amarathus Hybridus l). Jurnal Ilmiah Maternal ISSN: 2541-3120. Vol.II No. 2 Oktober 2017.

Rukmana, R. Bayam, Bertanam dan Pengolahan Pascapanen. Yogyakarta: Penerbit Kanisius. 2006;2-9

Saifudin. Pelayanan Maternal dan Neonatal. Jakarta. 2010; 82, 93-95

Samhadi. Malnutrisi, Keteledoran Sebuah Bangsa 2008 [diakses tanggal 28 September 2007]. Tersedia di: www.kompas.com.

SDKI. Survey Demografi Kependudukan Indonesia AKI dan AKB Tahun 2012. http://www.depkes.co.id. Diakses tanggal 7 Maret 2014.

Sukrat B. and Sirichotiyakul S. The prevalence and cause of anemia during pregnancy in Maharaj Nakorn Chiang Mai Hoapital. J. Med Assoc. Thai 2006; 89(suppl 4): S142-146

Susanti L, dkk. Formulasi dan uji stabilitas krim ekstrak etanolik daun bayam duri (amaranthus spinosus 1.). Universitas Indonesia. Jurnal nasional. 2008

Wahidiyat I \& Amalia P. Gangguan sintesa hemoglobin dalam buku ajar hematologi ontologi. Badan Penerbit IDAI. Jakarta.2009. 103112;205-215 
